\section{Efeitos da exposição a agrotóxicos sobre o sistema auditivo periférico e central: uma revisão sistemática}

\author{
Peripheral and central auditory effects of pesticide \\ exposure: a systematic review
}

\author{
Efectos de la exposición a los pesticidas en el \\ sistema auditivo periférico y central: \\ una revisión sistemática
}

\begin{abstract}
The World Health Organization reports a total of 3 million annual cases of acute pesticide poisoning (2.1 million cases in the developing countries alone). Pesticide use has reached alarming proportions in Brazil in the last decade. Pesticide sales skyrocketed from 2001 to 2008, making Brazil the world's leading consumer of poisons. This study aimed to assess whether pesticide exposure causes peripheral or central auditory disorders and thus focused on the importance of hearing tests in populations with acute or chronic exposure. This was a systematic review of studies on the effects of pesticide exposure on the auditory system. The context and methodological quality of the full texts were analyzed. The review identified 143 studies on the theme, 16 of which met the inclusion criteria. All articles showed that pesticide exposure is ototoxic and leads to hearing loss.
\end{abstract}

Pesticides; Hearing Loss; Central Hearing Loss; Environmental Health; Review
Maria Isabel Kós 1,2

Ana Cristina Hoshino 1

Carmen Ildes Fróes Asmus 1

Raphael Mendonça 1

Armando Meyer 1

\section{Resumo}

De acordo com a Organização Mundial da Saúde, as intoxicações agudas por agrotóxicos são da ordem de 3 milhões anuais, com 2,1 milhões de casos só nos países em desenvolvimento. $\mathrm{Na}$ última década, no Brasil, o uso de agrotóxicos assumiu proporções assustadoras. Entre 2001 2008 a venda desses produtos saltou, quando o país alcançou a posição de maior consumidor mundial de venenos. O objetivo deste estudo foi avaliar por meio de uma revisão sistemática se a exposição ao agrotóxico causa alterações auditivas no sistema auditivo periférico/central, atentando assim para a importância da avaliação auditiva em populações expostas de forma crônica ou aguda. Trata-se de uma revisão sistemática dos estudos publicados sobre os efeitos da exposição ao agrotóxico no sistema auditivo. Analisaram-se os trabalhos contemplados na integra e também sua qualidade metodológica. A pesquisa identificou 143 estudos sobre o tema, sendo que 16 se enquadraram nos critérios de inclusão. Todos os artigos analisados evidenciaram que a exposição ao agrotóxico é ototóxica e induz ao dano às vias auditivas.

Praguicidas; Perda Auditiva; Perda Auditiva Central; Saúde Ambiental; Revisão 


\section{Introdução}

De acordo com a Organização Mundial da Saúde (OMS), as intoxicações agudas por agrotóxicos são da ordem de 3 milhões anuais, com 2,1 milhões de casos só nos países em desenvolvimento. O número de mortes atinge 20 mil em todo o mundo e 14 mil nos países do terceiro mundo. Mas, acreditam os especialistas, as estatísticas reais devem ser ainda maiores, pois há falta de documentação a respeito das intoxicações subagudas, causadas por exposição moderada ou leve a produtos de alta toxicidade e de aparecimento lento com sintomatologia subjetiva; e das intoxicações crônicas que requerem meses ou anos de exposição e tardiamente revelam danos à saúde.

Na última década, no Brasil, o uso de agrotóxicos assumiu proporções assustadoras. Entre 2001 e 2008, a venda desses produtos saltou de pouco mais de US\$ 2 bilhões para mais de US\$ 7 bilhões, quando o país alcançou a posição de maior consumidor mundial de venenos 1 . Levantamentos realizados pelo Instituto Brasileiro de Geografia e Estatística (IBGE; http://www.ibge. gov.br/home/estatistica/indicadores/industria/ pimpfagro_nova/default.shtm, acessado em Out/2012) 2 e pelo Sindicato Nacional da Indústria de Produtos para Defesa Agrícola (SINDAG), em 2009, mostraram um crescimento de 4,59\% da área cultivada no período entre 2004 e 2008. Enquanto que no mesmo período as quantidades vendidas de agrotóxicos subiram aproximadamente $44,6 \% 2$.

No Brasil, em 2009 foram registrados 188 óbitos relacionados ao uso de agrotóxicos, o que gerou uma letalidade de $3,26 \%$ para o país como um todo, segundo o Sistema Nacional de Informações Tóxico-Farmacológicas (SINITOX; http:// www.fiocruz.br/sinitox, acessado em Out/2012), sendo que a maior letalidade foi gerada pelos agrotóxicos de uso agrícola. Ainda conforme o SINITOX, dos 5.612 casos de intoxicação ocupacional registrados naquele ano, $1.163(20,7 \%)$ foram causados por agrotóxicos.

De acordo com os dados divulgados pelo IBGE em 2010, nos nove anos anteriores houve um aumento médio de $11 \%$ ao ano na venda de agrotóxico. A maior utilização dessas substâncias é na agricultura, mas elas também são utilizadas na saúde pública, na eliminação e no controle de vetores transmissores de doenças endêmicas, e ainda no tratamento de madeira para construção, no armazenamento de grãos e sementes, na produção de flores, para combate de piolhos e outros parasitas, na pecuária etc. Além da exposição ocupacional, a contaminação ambiental coloca em risco de intoxicação outros grupos populacionais, como as famílias dos agricultores e, em menor grau, a população em geral, que tem a possibilidade de intoxicar-se principalmente na ingestão de alimentos contaminados 3 .

Os efeitos nocivos do uso de agrotóxicos para a saúde humana têm sido objeto de diversos estudos elaborados por profissionais da saúde, os quais têm detectado a presença dessas substâncias em amostras de sangue humano, no leite materno e em resíduos presentes em alimentos consumidos pela população em geral, apontando para a possibilidade de ocorrência de anomalias congênitas 4 , de câncer 5 , de doenças mentais 6 , de disfunções na reprodutividade humana 7 relacionadas ao uso de agrotóxicos 8 .

Além disso, estudos com substância química têm associado alterações auditivas com o uso de drogas ototóxicas, como na exposição a solventes orgânicos 9 e agrotóxicos ${ }^{10}$. Até então, todos os trabalhos sobre os danos auditivos relacionados à saúde de trabalhadores eram associados quase que exclusivamente aos riscos de exposição ao ruído ${ }^{11}$.

Muitas vezes a intoxicação ocupacional e ambiental por agrotóxicos é lenta e silenciosa, e as populações podem não sentir dificuldades auditivas que possam ser demonstradas em um audiograma, mas no seu cotidiano perdem a qualidade sonora de uma boa compreensão de fala, o que pode se refletir na dificuldade escolar e mesmo na comunicação com o meio social 12.

Alguns estudos têm sido realizados tentando associar danos no sistema auditivo periférico e/ ou central à exposição ao agrotóxico, sendo que a grande maioria tem apresentando resultados positivos para essa associação. Apesar de ser um tema que ainda necessita ser muito explorado, nenhum trabalho de revisão sistemática foi realizado sobre o assunto.

O objetivo deste estudo foi avaliar por meio de uma revisão sistemática se a exposição ao agrotóxico causa alterações auditivas no sistema auditivo periférico e/ou central, atentando assim para a importância da avaliação auditiva em populações expostas de forma crônica ou aguda.

\section{Métodos}

Foi realizada uma revisão sistemática dos trabalhos publicados a respeito dos efeitos sobre o sistema auditivo periférico e/ou central relacionados à exposição ao agrotóxico, de janeiro de 1966 a junho de 2012, período coberto pelo conjunto de bases de dados disponíveis.

Os critérios de inclusão foram: artigos originais de pesquisa, resumos de congressos específicos e trabalhos de mestrado e doutorado publicados nos anos de 1966 a 2012, em portu- 
guês, inglês, francês e espanhol, que estudaram os efeitos agudos ou crônicos do agrotóxico nas vias auditivas periféricas e/ou centrais. Puderam ser incluídos todos os tipos de estudo: ensaio clínico, estudo de coorte e caso controle, em qualquer idioma. Não houve restrição com relação ao sexo e idade das populações estudadas, nem ao tempo de exposição. Foram excluídos artigos de revisão, metanálise, editoriais e relatos de casos e artigos que relacionavam alterações auditivas com presença de ruído, e não com a exposição ao agrotóxico.

Foi realizada uma busca para identificar estudos que atendessem aos critérios de inclusão e exclusão estabelecidos. Na fase de busca não houve restrição com relação ao idioma dos artigos. Para isso, foram pesquisados por três revisores independentes os bancos de dados MEDLINE, de janeiro de 1966 a junho de 2012; Literatura Latino-Americana e do Caribe em Ciências da Saúde (LILACS), de janeiro de 1982 a junho de 2012; Scientific Electronic Library Online (SciELO), de janeiro de 1997 a junho de 2012; Web of Science, Science Direct e Scopus. Foram ainda realizadas buscas manuais por referências citadas nos artigos solicitados, e eletrônicas em sítios da Internet relacionados ao tema como Excerpta Medica, versão on-line (Embase), Agência Nacional de Vigilância Sanitária (ANVISA) e SINITOX, em sítios de associações e academias da área de audiologia como Academia Brasileira de Audiologia (ABA), The International Congress of Audiology (ICA), American Academy of Audiology (AAA), em busca de estudos apresentados em anais de congressos e em bancos de teses como o da Universidade de São Paulo (USP), Universidade Federal de Santa Maria (UFSM), Fundação Oswaldo Cruz (Fiocruz) e Instituto de Estudos em Saúde Coletiva da Universidade Federal do Rio de Janeiro (IESC/UFRJ). Os descritores utilizados, combinados entre si, foram: "audição" ou "hearing", "perda auditiva" ou "hearing loss", "alteração cognitiva" ou "cognitive effects", "audiometria" ou "audiometry" e "organofosforado" ou "organophosphates" ou "pesticida" ou "pesticides".

As referências dos trabalhos selecionados por meio da pesquisa nos bancos de dados foram examinadas em busca de artigos que atendessem aos critérios de seleção. Todos os estudos selecionados foram inicialmente analisados pelos três revisores segundo os seus resumos. Aqueles em que o estudo pesquisou associação do agrotóxico com alteração auditiva foram analisados na íntegra.

Os dados de cada trabalho foram coletados, independentemente, por dois revisores usandose formulários pré-delineados, que incluíram: variáveis correspondentes aos critérios de elegibilidade, variáveis referentes aos indivíduos envolvidos nos estudos (idade, sexo, ocupação), tipo de estudo (seccional, coorte, caso controle), variáveis de exposição (crônica ou aguda), número de indivíduos do estudo, presença de grupo controle, utilização de biomarcadores, tipo de avaliação realizada no estudo (questionários, audiometria, emissão otoacústica, imitanciometria, potencial evocado e/ou testes cognitivos) e conclusão compatível com os resultados.

Os trabalhos foram avaliados quanto à qualidade metodológica. Foi desenvolvida uma tabela, adaptada da avaliação de qualidade da Cochrane Collaboration 13, do resumo de risco de viés. Foram analisados oito itens nos artigos: especificação dos critérios de inclusão da população; presença de justificativa para o tamanho da amostra; presença de grupo controle; ausência de viés de seleção, aferição e perda; qualidade da avaliação realizada para pesquisar as vias auditivas; exposição somente a agrotóxico; presença de biomarcador; e a conclusão compatível com os resultados. Cada uma dessas questões foi respondida com "sim" ou "não".

\section{Resultados}

A pesquisa eletrônica identificou nas bases de dados 135 estudos publicados sobre o tema; foram identificados mais oito estudos por meio de pesquisas por referência bibliográfica de forma manual, sendo que um deles é uma tese, e não foi encontrado nenhum tema livre. As principais revistas em que os trabalhos foram encontrados são: Journal of Agricultural Safety and Health (14), American Journal of Industrial Medicine (13) e Journal of Agromedicine (7).

Inicialmente foram excluídos 42 estudos por estarem repetidos. Dos 101 restantes, 64 foram excluídos por serem revisões de literatura, estudos realizados em laboratório ou com cobais, ou por não estarem associados ao assunto pesquisado. Outros 4 resumos foram excluídos por estarem em outra língua (polonês, russo e alemão). Os 33 trabalhos restantes foram analisados com os textos completos, sendo que 17 foram excluídos por associarem as alterações auditivas somente com exposição ao ruído, sem abordarem o uso do agrotóxico, ou por estudarem somente alterações vestibulares (do labirinto) 14,15,16,17,18,19,20,21,22,23,24,25,26,27,28,29,30. Somente 16 trabalhos satisfizeram os critérios de inclusão. Apesar de a pesquisa ter abrangido estudos a partir de 1966, só foram encontrados artigos relacionados ao assunto estudado a partir de 2000 (Figura 1). 


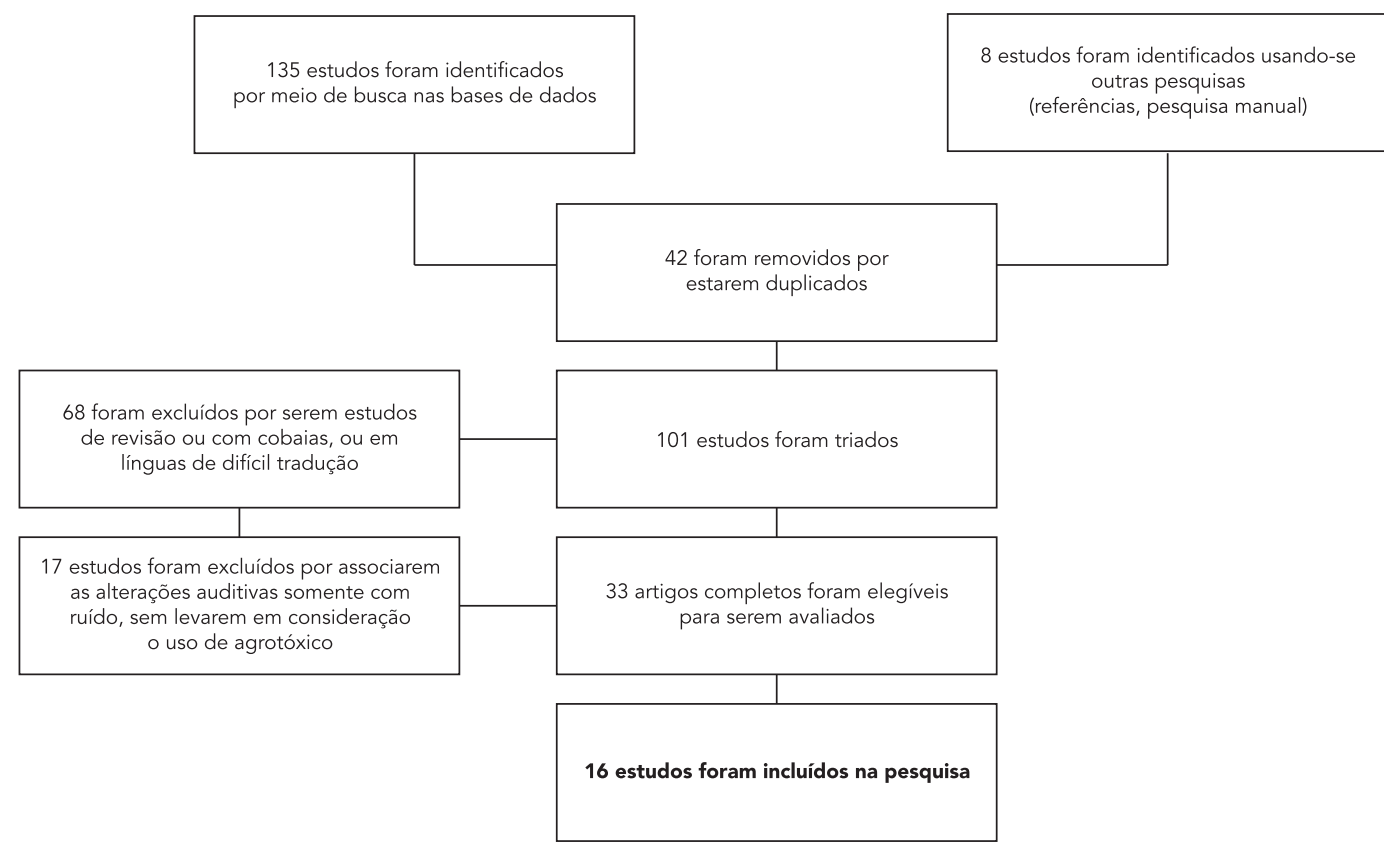

A Tabela 1 traz informações sobre os estudos incluídos nesta revisão. Dos 16 artigos que se enquadraram nos critérios de inclusão, dois foram realizados com crianças e adolescentes, avaliando a exposição ambiental. Um desses artigos avaliou indivíduos que tentaram se suicidar com doses elevadas de agrotóxico, estudando a exposição aguda; outro analisou pilotos agrícolas com exposição aos agrotóxicos, e 12 avaliaram agricultores com exposição crônica a pesticidas. Onze artigos foram publicados em inglês e cinco em língua portuguesa, sendo que seis estudos foram realizados nos Estados Unidos, três no Sri Lanka, um na Alemanha e seis no Brasil. A maior parte abordou o efeito crônico de agrotóxico em trabalhadores rurais e/ou familiares, sendo que quatro deles estudaram também o efeito da exposição ao ruído ocupacional, emitido principalmente pelo trator. Em conjunto, os estudos cobriram uma população de 20.763 indivíduos, variando de estudo com grupo de 32 indivíduos a estudo com grupo de 14.229. Entre esses estudos somente um realizou pesquisa de biomarcador utilizando pesquisa de metabólito para organofosforado na urina. $\mathrm{O}$ trabalho que avaliou a exposição aguda fez o diagnóstico por meio de avaliação clínica do quadro de sintomas e sinais, todos os outros avaliaram a exposição a agrotóxicos usando questionários.

A população estudada foi principalmente de agricultores expostos a agrotóxicos (12 estudos) e dois artigos foram voltados para pulverizadores de veneno para dengue. Foram realizadas pesquisas somente usando questionário para avaliar a alteração auditiva (dois), que foram os estudos seccionais. Três avaliaram o processamento auditivo central, nove a audição periférica por meio da audiometria tonal e vocal, e três as vias auditivas centrais utilizando o potencial evocado auditivo de média e longa latências.

Dentre os 16 trabalhos encontrados, 6 deles possuíam delineamento seccional; 8 eram estudos de coorte retrospectiva; e 2 foram descritivos. Com relação ao tipo de exposição, 3 foram estudos com exposição ambiental, 3 com exposição ocupacional e ambiental e 12 somente com exposição ocupacional. Sobre os sintomas, 8 avaliaram as vias auditivas utilizando a audiometria tonal; 3 avaliaram com potenciais evocados; 3 avaliaram disfunção cognitiva/processamento auditivo; e 2 utilizaram somente questionário para verificar a capacidade auditiva. 
Tabela 1

Descrição dos estudos selecionados para a revisão sistemática.

\begin{tabular}{|c|c|c|c|c|c|c|c|c|c|}
\hline $\begin{array}{l}\text { Referência } \\
\text { (ano) }\end{array}$ & $\begin{array}{l}\text { População } \\
\text { exposta }\end{array}$ & $\begin{array}{l}\text { Substân- } \\
\text { cia quí- } \\
\text { mica }\end{array}$ & $\begin{array}{l}\text { Tipo de } \\
\text { estudo }\end{array}$ & $\begin{array}{c}\text { Tipo de } \\
\text { exposição }\end{array}$ & $\mathrm{n}$ & $\begin{array}{c}\text { Forma de } \\
\text { mensuração da } \\
\text { exposição }\end{array}$ & $\begin{array}{c}\text { Instrumentos } \\
\text { de avaliação do } \\
\text { desfecho }\end{array}$ & Resultado & $\begin{array}{l}\text { Resultados } \\
\text { estatísticos }\end{array}$ \\
\hline $\begin{array}{l}\text { Beckett et } \\
\text { al. } 37 \text { (2000) }\end{array}$ & $\begin{array}{l}\text { Fazen- } \\
\text { deiros }\end{array}$ & $\begin{array}{l}\text { Agrotó- } \\
\text { xicos }\end{array}$ & $\begin{array}{l}\text { Estudo } \\
\text { seccio- } \\
\text { nal }\end{array}$ & $\begin{array}{l}\text { Ocupa- } \\
\text { cional e } \\
\text { ambien- } \\
\text { tal }\end{array}$ & 1.727 & $\begin{array}{c}\text { Por meio do } \\
\text { questionário } \\
\text { foram } \\
\text { comparados os } \\
\text { agricultores que } \\
\text { manipulavam } \\
\text { diretamente } \\
\text { os agrotóxicos } \\
\text { (exposição } \\
\text { intensa), } \\
\text { indiretamente } \\
\text { (exposição } \\
\text { moderada) e as } \\
\text { mulheres, que } \\
\text { faziam o trabalho } \\
\text { doméstico } \\
\text { (exposição leve). }\end{array}$ & $\begin{array}{l}\text { Questionário de } \\
\text { função auditiva } \\
\text { em todos } \\
\text { (1.727), em } \\
\text { parte do grupo } \\
\text { audiometria tonal } \\
\text { (416). }\end{array}$ & $\begin{array}{c}\text { Os achados } \\
\text { sugeriram que } \\
\text { os fazendeiros } \\
\text { apresentaram } \\
\text { uma alta } \\
\text { prevalência } \\
\text { de alterações } \\
\text { auditivas, } \\
\text { que afetam a } \\
\text { qualidade de } \\
\text { vida do indivíduo, } \\
\text { principalmente se } \\
\text { associada com o } \\
\text { envelhecimento, } \\
\text { sexo masculino, } \\
\text { baixa } \\
\text { escolaridade, } \\
\text { uso de outros } \\
\text { produtos } \\
\text { químicos e } \\
\text { exposição a } \\
\text { ruído. }\end{array}$ & 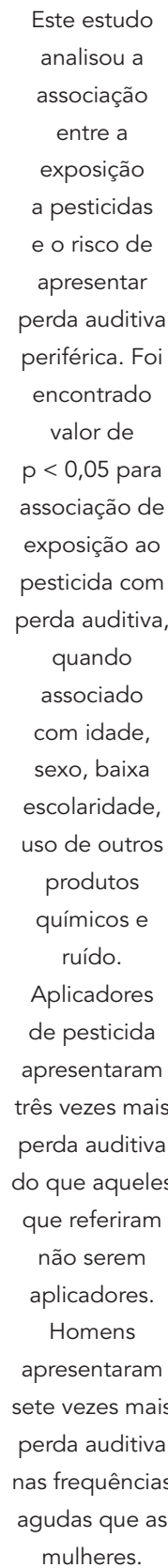 \\
\hline
\end{tabular}


Tabela 1 (continuação)

\begin{tabular}{|c|c|c|c|c|c|c|c|c|c|}
\hline $\begin{array}{l}\text { Referência } \\
\text { (ano) }\end{array}$ & $\begin{array}{c}\text { População } \\
\text { exposta }\end{array}$ & $\begin{array}{l}\text { Substân- } \\
\text { cia quí- } \\
\text { mica }\end{array}$ & $\begin{array}{l}\text { Tipo de } \\
\text { estudo }\end{array}$ & $\begin{array}{c}\text { Tipo de } \\
\text { exposição }\end{array}$ & $\mathrm{n}$ & $\begin{array}{l}\text { Forma de } \\
\text { mensuração da } \\
\text { exposição }\end{array}$ & $\begin{array}{c}\text { Instrumentos } \\
\text { de avaliação do } \\
\text { desfecho }\end{array}$ & Resultado & $\begin{array}{l}\text { Resultados } \\
\text { estatísticos }\end{array}$ \\
\hline $\begin{array}{l}\text { Bosma et } \\
\text { al. } 48 \text { (2000) }\end{array}$ & $\begin{array}{c}\text { Indivíduos } \\
\text { expostos } \\
\text { a organo- } \\
\text { fosforado, } \\
\text { solventes } \\
\text { orgânicos, } \\
\text { metais } \\
\text { e outras } \\
\text { substân- } \\
\text { cias quí- } \\
\text { micas }\end{array}$ & $\begin{array}{c}\text { Agro- } \\
\text { tóxicos, } \\
\text { solventes } \\
\text { orgânicos, } \\
\text { metais e/ } \\
\text { ou outras } \\
\text { substân- } \\
\text { cias tóxi- } \\
\text { cas }\end{array}$ & $\begin{array}{l}\text { Estudo } \\
\text { seccional }\end{array}$ & $\begin{array}{c}\text { Crônico, } \\
\text { ocupacio- } \\
\text { nal e am- } \\
\text { biental }\end{array}$ & 1.604 & $\begin{array}{c}\text { Foram } \\
\text { comparados } \\
\text { dois grupos; } \\
\text { o primeiro } \\
\text { de indivíduos } \\
\text { expostos a } \\
\text { agrotóxicos } \\
\text { e outras } \\
\text { substâncias } \\
\text { químicas e o } \\
\text { outro de não } \\
\text { expostos. }\end{array}$ & $\begin{array}{l}\text { Questionário } \\
\text { das funções } \\
\text { cognitivas e } \\
\text { pesquisa do } \\
\text { processamento } \\
\text { auditivo central. }\end{array}$ & $\begin{array}{l}\text { Os achados do } \\
\text { estudo sugeri- } \\
\text { ram que o risco } \\
\text { de desenvolver } \\
\text { alteração do } \\
\text { processamento } \\
\text { auditivo central } \\
\text { leve é aproxima- } \\
\text { damente cinco } \\
\text { vezes maior no } \\
\text { grupo exposto } \\
\text { a pesticidas do } \\
\text { que no grupo } \\
\text { não exposto, } \\
\text { esse tipo de alte- } \\
\text { ração irá afetar a } \\
\text { comunicação do } \\
\text { indivíduo, prin- } \\
\text { cipalmente em } \\
\text { ambientes com } \\
\text { ruído. }\end{array}$ & $\begin{array}{c}\text { Nestes estudos, } \\
\text { os expostos } \\
\text { a pesticidas } \\
\text { apresentaram } \\
\text { odds ratio } \\
\text { ajustada para os } \\
\text { outros produtos } \\
\text { químicos de OR: } \\
4,94 \text { (IC95\%: } \\
\text { 1,53 - 16,1) de } \\
\text { desenvolverem } \\
\text { alteração de } \\
\text { processamento } \\
\text { auditivo central } \\
\text { leve. }\end{array}$ \\
\hline $\begin{array}{l}\text { Hwang et } \\
\text { al. } 52 \text { (2001) }\end{array}$ & $\begin{array}{l}\text { Fazen- } \\
\text { deiros } \\
\text { ou resi- } \\
\text { dentes } \\
\text { próxi- } \\
\text { mos às } \\
\text { fazendas }\end{array}$ & $\begin{array}{l}\text { Agrotó- } \\
\text { xico }\end{array}$ & $\begin{array}{l}\text { Estudo } \\
\text { de coor- } \\
\text { te retros- } \\
\text { pectiva }\end{array}$ & $\begin{array}{l}\text { Ocupacio- } \\
\text { nal e am- } \\
\text { biental }\end{array}$ & 1.622 & $\begin{array}{c}\text { Por meio de } \\
\text { questionário que } \\
\text { analisou a exposi- } \\
\text { ção a agrotóxicos } \\
\text { foram divididos } \\
\text { os grupos em } \\
\text { quartil de expo- } \\
\text { sição. }\end{array}$ & $\begin{array}{c}\text { Questionário } \\
\text { sobre dificuldade } \\
\text { auditiva. }\end{array}$ & $\begin{array}{c}\text { Este estudo } \\
\text { analisou a } \\
\text { percepção } \\
\text { dos indivíduos } \\
\text { com relação } \\
\text { a sua própria } \\
\text { audição. Foi } \\
\text { observada } \\
\text { maior } \\
\text { prevalência } \\
\text { de pessoas } \\
\text { que sentem } \\
\text { dificuldade de } \\
\text { escutar nos } \\
\text { fazendeiros que } \\
\text { apresentam } \\
\text { maior } \\
\text { exposição aos } \\
\text { agrotóxicos, } \\
\text { agravada pela } \\
\text { exposição a } \\
\text { ruído. }\end{array}$ & $\begin{array}{c}\text { Este estudo anali- } \\
\text { sou a prevalência } \\
\text { de agricultores } \\
\text { que sentem } \\
\text { dificuldade audi- } \\
\text { tiva divididos em } \\
\text { quartil pelo grau } \\
\text { de exposição } \\
\text { aos pesticidas; } \\
\text { o 1ㅇ quartil foi } \\
\text { o de menos ex- } \\
\text { postos; os dados } \\
\text { foram ajustados } \\
\text { pela exposição a } \\
\text { ruído. } \\
\text { 1ㅇ quartil: } 8,6 \% \\
\text { 1,00 } \\
\text { 2o quartil: } 16,8 \% \\
\text { 1,94 (IC95\%: } \\
\text { 1,32-2,85) } \\
\text { 3ㅇ quartil: } 26,7 \% \\
\text { 3,09 (IC95\%: } \\
\text { 2,17-4,41) } \\
\text { 4o quartil: } 35,9 \% \\
\text { 4,15 (IC95\%: } \\
2,95-5,85) .\end{array}$ \\
\hline
\end{tabular}

(continua) 
Tabela 1 (continuação)

\begin{tabular}{|c|c|c|c|c|c|c|c|c|c|}
\hline $\begin{array}{l}\text { Referência } \\
\text { (ano) }\end{array}$ & $\begin{array}{l}\text { População } \\
\text { exposta }\end{array}$ & $\begin{array}{l}\text { Substân- } \\
\text { cia quí- } \\
\text { mica }\end{array}$ & $\begin{array}{l}\text { Tipo de } \\
\text { estudo }\end{array}$ & $\begin{array}{c}\text { Tipo de } \\
\text { exposição }\end{array}$ & $\mathrm{n}$ & $\begin{array}{l}\text { Forma de } \\
\text { mensuração da } \\
\text { exposição }\end{array}$ & $\begin{array}{l}\text { Instrumentos } \\
\text { de avaliação do } \\
\text { desfecho }\end{array}$ & Resultado & $\begin{array}{l}\text { Resultados } \\
\text { estatísticos }\end{array}$ \\
\hline $\begin{array}{l}\text { Teixeira et } \\
\text { al. } 31 \text { (2002) }\end{array}$ & $\begin{array}{l}\text { Pulveriza- } \\
\text { dores de } \\
\text { veneno } \\
\text { contra } \\
\text { dengue }\end{array}$ & $\begin{array}{l}\text { Organo- } \\
\text { fosforado } \\
\text { e piretroi- } \\
\text { des }\end{array}$ & $\begin{array}{l}\text { Estudo } \\
\text { de coorte } \\
\text { retrospec- } \\
\text { ti-va }\end{array}$ & $\begin{array}{c}\text { Ocupacio- } \\
\text { nal }\end{array}$ & 152 & $\begin{array}{l}\text { Foram utilizados } \\
\text { dois grupos, um } \\
\text { de pulverizadores } \\
\text { e outro dos que } \\
\text { trabalhavam } \\
\text { no setor } \\
\text { administrativo } \\
\text { (grupo controle). }\end{array}$ & $\begin{array}{l}\text { Pesquisa do } \\
\text { processamento } \\
\text { auditivo central. }\end{array}$ & $\begin{array}{c}\text { Os resultados } \\
\text { sugerem que } \\
\text { a exposição a } \\
\text { piretroides e } \\
\text { organofosforado } \\
\text { afeta as funções } \\
\text { auditivas centrais, } \\
\text { dificultando a } \\
\text { compreensão } \\
\text { das palavras, } \\
\text { principalmente } \\
\text { na discriminação, } \\
\text { situações com } \\
\text { ruído. }\end{array}$ & $\begin{array}{c}\text { Foi observado } \\
\text { que } 56 \% \text { dos } \\
\text { expostos } \\
\text { apresentaram } \\
\text { alterações de } \\
\text { processamento } \\
\text { auditivo central } \\
\text { com RR }=7,58 \\
\text { para o grupo } \\
\text { exposto (IC95\%: } \\
2,9-19,8), \\
\text { comparando com } \\
\text { o grupo dos não } \\
\text { expostos. }\end{array}$ \\
\hline $\begin{array}{l}\text { Teixeira et } \\
\text { al. } 10 \text { (2003) }\end{array}$ & $\begin{array}{l}\text { Pulveri- } \\
\text { zadores } \\
\text { de } \\
\text { veneno } \\
\text { contra } \\
\text { dengue }\end{array}$ & $\begin{array}{l}\text { Orga- } \\
\text { nofosfo- } \\
\text { rado e } \\
\text { piretroi- } \\
\text { des }\end{array}$ & $\begin{array}{l}\text { Estudo } \\
\text { de coor- } \\
\text { te retros- } \\
\text { pectiva }\end{array}$ & $\begin{array}{l}\text { Ocupa- } \\
\text { cional }\end{array}$ & 149 & $\begin{array}{l}\text { Foi utilizado um } \\
\text { questionário que } \\
\text { dividiu os grupos } \\
\text { em expostos } \\
\text { a inseticidas } \\
\text { e expostos a } \\
\text { inseticidas e } \\
\text { ruído. }\end{array}$ & $\begin{array}{l}\text { Questionário } \\
\text { para avaliar a } \\
\text { exposição e } \\
\text { audiometria tonal } \\
\text { e vocal. }\end{array}$ & $\begin{array}{l}\text { Foi analisada } \\
\text { a exposição } \\
\text { a inseticidas } \\
\text { e comparado } \\
\text { com avaliação } \\
\text { auditiva perifé- } \\
\text { rica. Os resul- } \\
\text { tados sugerem } \\
\text { que as exposi- } \\
\text { ções crônicas } \\
\text { aos inseticidas } \\
\text { piretroides e or- } \\
\text { ganofosforados } \\
\text { podem afetar o } \\
\text { sistema auditivo } \\
\text { periférico, inde- } \\
\text { pendentemente } \\
\text { de exposição } \\
\text { ao ruído. }\end{array}$ & $\begin{array}{c}\text { Foi observado } \\
\text { que dentre } \\
\text { os expostos } \\
\text { apenas aos } \\
\text { inseticidas } \\
63,8 \% \\
\text { apresentaram } \\
\text { algum grau de } \\
\text { PA, com tempo } \\
\text { médio para } \\
\text { desenvolver a } \\
\text { PA de } 7,3 \text { anos. } \\
\text { Para o grupo } \\
\text { com exposição } \\
\text { a ruído e } \\
\text { agrotóxico a PA } \\
\text { foi de } 66,7 \% \text {, } \\
\text { com tempo } \\
\text { médio para } \\
\text { desenvolvê-la } \\
\text { de } 3,4 .\end{array}$ \\
\hline $\begin{array}{l}\text { Manjabos- } \\
\text { co et al. } 32 \\
\text { (2004) }\end{array}$ & $\begin{array}{l}\text { Traba- } \\
\text { Ihadores } \\
\text { rurais }\end{array}$ & $\begin{array}{l}\text { Agrotó- } \\
\text { xicos }\end{array}$ & $\begin{array}{l}\text { Estudo } \\
\text { de caso } \\
\text { controle }\end{array}$ & $\begin{array}{l}\text { Ocupa- } \\
\text { cional }\end{array}$ & 84 & $\begin{array}{c}\text { Foram } \\
\text { comparados } \\
\text { dois grupos, } \\
\text { o primeiro de } \\
\text { indivíduos que } \\
\text { trabalhavam em } \\
\text { uma empresa } \\
\text { agrícola expostos } \\
\text { a agrotóxicos } \\
\text { e o segundo } \\
\text { sem exposição } \\
\text { a agrotóxicos e } \\
\text { ruído. }\end{array}$ & $\begin{array}{l}\text { Questionário } \\
\text { para avaliar as } \\
\text { queixas auditivas } \\
\text { e audiometria } \\
\text { tonal e vocal. }\end{array}$ & $\begin{array}{l}\text { O fator ocu- } \\
\text { pacional dos } \\
\text { trabalhadores } \\
\text { da empresa } \\
\text { agrícola es- } \\
\text { tudada teve } \\
\text { grande impacto } \\
\text { nos achados } \\
\text { audiométricos } \\
\text { dos indivíduos } \\
\text { avaliados, não } \\
\text { só o ruído mas } \\
\text { a exposição ao } \\
\text { agrotóxico tive- } \\
\text { ram influência } \\
\text { na audição. }\end{array}$ & $\begin{array}{l}\text { No estudo } \\
\text { foi observado } \\
\text { que o grupo } \\
\text { dos expostos } \\
\text { apresentou } \\
60 \% \text { (25) dos } \\
\text { agricultores } \\
\text { limiares } \\
\text { alterados. }\end{array}$ \\
\hline
\end{tabular}

(continua) 
Tabela 1 (continuação)

\begin{tabular}{|c|c|c|c|c|c|c|c|c|c|}
\hline $\begin{array}{l}\text { Referência } \\
\text { (ano) }\end{array}$ & $\begin{array}{l}\text { População } \\
\text { exposta }\end{array}$ & $\begin{array}{l}\text { Substân- } \\
\text { cia quí- } \\
\text { mica }\end{array}$ & $\begin{array}{l}\text { Tipo de } \\
\text { estudo }\end{array}$ & $\begin{array}{c}\text { Tipo de } \\
\text { exposição }\end{array}$ & $n$ & $\begin{array}{c}\text { Forma de } \\
\text { mensuração da } \\
\text { exposição }\end{array}$ & $\begin{array}{c}\text { Instrumentos } \\
\text { de avaliação do } \\
\text { desfecho }\end{array}$ & Resultado & $\begin{array}{l}\text { Resultados } \\
\text { estatísticos }\end{array}$ \\
\hline & & & & & & & & & $\begin{array}{c}\text { Desses, } \\
23 \text { foram } \\
\text { sugestivos de } \\
\text { perdas auditivas } \\
\text { ocupacionais, } \\
\text { incluindo as } \\
\text { PAIR, e por } \\
\text { ototóxicos } \\
\text { (17\% expostos } \\
\text { somente a ruído } \\
\text { e } 83 \% \text { a ruído } \\
\text { e agrotóxicos). } \\
\text { O zumbido } \\
\text { frequente } \\
\text { esteve presente } \\
\text { em } 57 \% \text { (13) } \\
\text { dos casos. No } \\
\text { grupo controle, } \\
\text { apenas } 7 \% \text { (3) } \\
\text { dos sujeitos } \\
\text { apresentaram } \\
\text { limiares } \\
\text { auditivos } \\
\text { alterados. }\end{array}$ \\
\hline $\begin{array}{l}\text { Choi et al. } 46 \\
(2005)\end{array}$ & $\begin{array}{c}\text { Traba- } \\
\text { Ihadores } \\
\text { rurais }\end{array}$ & $\begin{array}{l}\text { Agrotó- } \\
\text { xicos }\end{array}$ & $\begin{array}{l}\text { Estudo } \\
\text { seccio- } \\
\text { nal }\end{array}$ & $\begin{array}{l}\text { Ocupa- } \\
\text { cional }\end{array}$ & 150 & $\begin{array}{l}\text { Foi utilizado um } \\
\text { questionário } \\
\text { que comparou } \\
\text { os indivíduos } \\
\text { que utilizavam } \\
\text { inseticidas, } \\
\text { organofosforado } \\
\text { e os que } \\
\text { tiveram alguma } \\
\text { intoxicação } \\
\text { aguda. }\end{array}$ & $\begin{array}{c}\text { Questionário } \\
\text { que analisou a } \\
\text { exposição e au- } \\
\text { diometria tonal e } \\
\text { vocal. }\end{array}$ & $\begin{array}{c}\text { Este estudo } \\
\text { mostrou uma } \\
\text { evidência } \\
\text { substancial de } \\
\text { que a atividade } \\
\text { agrícola pode } \\
\text { trazer risco } \\
\text { para a audição, } \\
\text { causando } \\
\text { perda auditiva, } \\
\text { que traz } \\
\text { prejuízo para } \\
\text { comunicação. }\end{array}$ & $\begin{array}{l}\text { Neste estudo } \\
\text { foi realizada } \\
\text { uma analise } \\
\text { multivariada, foi } \\
\text { observada uma } \\
\text { RT para expostos } \\
\text { à inseticida de } \\
\text { 1,19 (IC95\%: } \\
\text { 1,04-1,35) e para } \\
\text { organofosforado } \\
\text { de 1,17 (IC95\%: } \\
\text { 1,03-1,31). A } \\
\text { RT para PA foi } \\
\text { elevada para } \\
\text { aqueles em que } \\
\text { ocorreram casos } \\
\text { agudos 1,81 } \\
\text { (IC95\%: 1,25- } \\
2,62) \text {. }\end{array}$ \\
\hline
\end{tabular}

(continua) 
Tabela 1 (continuação)

\begin{tabular}{|c|c|c|c|c|c|c|c|c|c|}
\hline $\begin{array}{l}\text { Referência } \\
\text { (ano) }\end{array}$ & $\begin{array}{l}\text { População } \\
\text { exposta }\end{array}$ & $\begin{array}{l}\text { Substân- } \\
\text { cia quí- } \\
\text { mica }\end{array}$ & $\begin{array}{l}\text { Tipo de } \\
\text { estudo }\end{array}$ & $\begin{array}{c}\text { Tipo de } \\
\text { exposição }\end{array}$ & $\mathrm{n}$ & $\begin{array}{c}\text { Forma de } \\
\text { mensuração da } \\
\text { exposição }\end{array}$ & $\begin{array}{c}\text { Instrumentos } \\
\text { de avaliação do } \\
\text { desfecho }\end{array}$ & Resultado & $\begin{array}{l}\text { Resultados } \\
\text { estatísticos }\end{array}$ \\
\hline $\begin{array}{l}\text { Lizardi et } \\
\text { al. } 38 \text { (2008) }\end{array}$ & $\begin{array}{c}\text { Crianças } \\
\text { hispânicas } \\
\text { morado- } \\
\text { ras de } \\
\text { uma co- } \\
\text { munidade } \\
\text { agrícola }\end{array}$ & $\begin{array}{l}\text { Organo- } \\
\text { fosfora- } \\
\text { dos }\end{array}$ & $\begin{array}{l}\text { Estudo } \\
\text { seccional }\end{array}$ & Ambiental & 48 & $\begin{array}{c}\text { Foi utilizada } \\
\text { pesquisa de } \\
\text { metabólitos para } \\
\text { organofosforado } \\
\text { na urina, para } \\
\text { pesquisar } \\
\text { exposição ao } \\
\text { agrotóxico. }\end{array}$ & $\begin{array}{c}\text { Pesquisa do } \\
\text { processamento } \\
\text { auditivo central. }\end{array}$ & $\begin{array}{c}\text { Em todas as } \\
\text { crianças foram } \\
\text { detectados níveis } \\
\text { mínimos de } \\
\text { metabólitos de } \\
\text { organofosforado. } \\
\text { Concentrações } \\
\text { elevadas de } \\
\text { metabólitos de } \\
\text { organofosforado } \\
\text { foram associadas } \\
\text { significantemente } \\
\text { com um } \\
\text { desempenho } \\
\text { mais pobre } \\
\text { nos testes de } \\
\text { processamento } \\
\text { auditivo central, } \\
\text { que podem } \\
\text { prejudicar o } \\
\text { desempenho } \\
\text { escolar. }\end{array}$ & $\begin{array}{c}\text { Neste estudo } \\
\text { foram observados } \\
\text { níveis altos de } \\
\text { concentração de } \\
\text { metabólitos de } \\
\text { organofosforado, } \\
\text { nos indivíduos } \\
\text { com maiores } \\
\text { concentrações } \\
\text { verificou-se } \\
\text { alto índice } \\
\text { de correlação } \\
\text { com erros } \\
\text { nos testes de } \\
\text { processamento } \\
\text { auditivo central, } \\
\text { com razão de } \\
\text { chance de: } r= \\
0.31 \text { ( } p=0.03 \text { ). }\end{array}$ \\
\hline $\begin{array}{l}\text { Crawford et } \\
\text { al. } 47 \text { (2008) }\end{array}$ & $\begin{array}{l}\text { Aplica- } \\
\text { dores } \\
\text { de pes- } \\
\text { ticidas/ } \\
\text { indivíduos } \\
\text { não ex- } \\
\text { postos } \\
\text { ocupacio- } \\
\text { nalmente }\end{array}$ & $\begin{array}{l}\text { Herbici- } \\
\text { das, in- } \\
\text { seticidas, } \\
\text { fungicidas } \\
\text { e fumi- } \\
\text { gantes }\end{array}$ & $\begin{array}{l}\text { Estudo } \\
\text { de coorte } \\
\text { retrospec- } \\
\text { tiva }\end{array}$ & $\begin{array}{c}\text { Ocupacio- } \\
\text { nal }\end{array}$ & 14.229 & $\begin{array}{l}\text { Foram utilizados } \\
\text { dois grupos: } \\
\text { o primeiro de } \\
\text { aplicadores de } \\
\text { pesticida e o } \\
\text { segundo de } \\
\text { trabalhadores } \\
\text { do hospital onde } \\
\text { foi realizada a } \\
\text { pesquisa (grupo } \\
\text { controle). }\end{array}$ & $\begin{array}{c}\text { Questionário } \\
\text { para avaliar as } \\
\text { queixas auditivas. }\end{array}$ & $\begin{array}{c}\text { O estudo mos- } \\
\text { trou que a per- } \\
\text { cepção de perda } \\
\text { auditiva está sig- } \\
\text { nificativamente } \\
\text { associada às ati- } \\
\text { vidades agrícolas, } \\
\text { e que podem ser } \\
\text { agravadas com } \\
\text { a presença de } \\
\text { ruído. }\end{array}$ & $\begin{array}{c}\text { Neste estudo } \\
\text { foi observado } \\
\text { que a queixa de } \\
\text { dificuldade na } \\
\text { audição no grupo } \\
\text { de expostos a } \\
\text { pesticidas na } \\
\text { melhor orelha } \\
\text { apresentou RR = } \\
\text { 1,62; para perda } \\
\text { assimétrica, RR } \\
\text { 1,67; e a queixa } \\
\text { de não escutar } \\
\text { bem registrada } \\
\text { por meio de } \\
\text { questionário foi } \\
\text { de RR = 1,96. } \\
\text { A exposição à } \\
\text { pesticida apre- } \\
\text { sentou OR = 1,19 } \\
\text { (IC95\%: 1,04- } \\
\text { 1,35) para perda } \\
\text { de audição, foi } \\
\text { realizado ajuste } \\
\text { para a varíavel } \\
\text { de confudimento } \\
\text { de exposição ao } \\
\text { ruído e idade. }\end{array}$ \\
\hline
\end{tabular}

(continua) 
Tabela 1 (continuação)

\begin{tabular}{|c|c|c|c|c|c|c|c|c|c|}
\hline $\begin{array}{l}\text { Referência } \\
\text { (ano) }\end{array}$ & $\begin{array}{c}\text { População } \\
\text { exposta }\end{array}$ & $\begin{array}{l}\text { Substân- } \\
\text { cia quí- } \\
\text { mica }\end{array}$ & $\begin{array}{l}\text { Tipo de } \\
\text { estudo }\end{array}$ & $\begin{array}{l}\text { Tipo de } \\
\text { exposição }\end{array}$ & $\mathrm{n}$ & $\begin{array}{c}\text { Forma de } \\
\text { mensuração da } \\
\text { exposição }\end{array}$ & $\begin{array}{l}\text { Instrumentos } \\
\text { de avaliação do } \\
\text { desfecho }\end{array}$ & Resultado & $\begin{array}{l}\text { Resultados } \\
\text { estatísticos }\end{array}$ \\
\hline $\begin{array}{l}\text { Renick et } \\
\text { al. } 49 \text { (2009) }\end{array}$ & $\begin{array}{l}\text { Crianças } \\
\text { e adoles- } \\
\text { centes } \\
\text { morado- } \\
\text { res de } \\
\text { cidades } \\
\text { rurais }\end{array}$ & $\begin{array}{c}\text { Agrotóxi- } \\
\text { cos }\end{array}$ & $\begin{array}{l}\text { Estudo } \\
\text { de coorte } \\
\text { retrospec- } \\
\text { tiva }\end{array}$ & $\begin{array}{l}\text { Ocupacio- } \\
\text { nal e am- } \\
\text { biental }\end{array}$ & 212 & $\begin{array}{l}\text { Neste } \\
\text { estudo foram } \\
\text { comparados } \\
\text { os resultados } \\
\text { realizados } \\
\text { com jovens } \\
\text { fazendeiros } \\
\text { a estudos } \\
\text { realizados } \\
\text { com dados } \\
\text { encontrados em } \\
\text { estudos nacionais } \\
\text { da mesma faixa } \\
\text { etária (Estados } \\
\text { Unidos). }\end{array}$ & $\begin{array}{l}\text { Questionário } \\
\text { para avaliar } \\
\text { a percepção } \\
\text { auditiva e } \\
\text { audiometria tonal } \\
\text { e vocal. }\end{array}$ & $\begin{array}{l}\text { O estudo sugeriu } \\
\text { que perda } \\
\text { auditiva é um } \\
\text { problema comum } \\
\text { nos fazendeiros } \\
\text { adultos, e que } \\
\text { talvez possa ser } \\
\text { um problema } \\
\text { para jovens } \\
\text { fazendeiros } \\
\text { também, o } \\
\text { que acarreta } \\
\text { problema na } \\
\text { comunicação. }\end{array}$ & $\begin{array}{l}\text { Neste estudo foi } \\
\text { observado que } \\
\text { aproximadamen- } \\
\text { te } 50 \% \text { dos jo- } \\
\text { vens fazendeiros } \\
\text { apresentaram } \\
\text { uma queda nas } \\
\text { altas frequências, } \\
\text { em particular a } \\
\text { de } 6.000 \mathrm{~Hz} \text {. Essa } \\
\text { perda é aproxi- } \\
\text { madamente } 2 \\
\text { vezes maior que } \\
\text { a da população } \\
\text { nacional. Esse } \\
\text { tipo de perda } \\
\text { ainda não traz } \\
\text { dificuldade para } \\
\text { compreensão, } \\
\text { mas é um estágio } \\
\text { inical para uma } \\
\text { alteração irrever- } \\
\text { sível. }\end{array}$ \\
\hline $\begin{array}{l}\text { Dassa- } \\
\text { nayake et } \\
\text { al. } 39 \text { (2009) }\end{array}$ & $\begin{array}{l}\text { Traba- } \\
\text { Ihadores } \\
\text { expostos } \\
\text { a organo- } \\
\text { fosforados }\end{array}$ & $\begin{array}{l}\text { Organo- } \\
\text { fosfora- } \\
\text { dos }\end{array}$ & $\begin{array}{l}\text { Estudo } \\
\text { seccional }\end{array}$ & $\begin{array}{c}\text { Ocupacio- } \\
\text { nal }\end{array}$ & 73 & $\begin{array}{l}\text { Foram utilizados } \\
\text { dois grupos: } \\
\text { o primeiro de } \\
\text { aplicadores de } \\
\text { pesticidas, e } \\
\text { o segundo de } \\
\text { trabalhadores } \\
\text { do hospital onde } \\
\text { foi realizada a } \\
\text { pesquisa (grupo } \\
\text { controle). }\end{array}$ & $\begin{array}{l}\text { Pesquisa do } \\
\text { potencial de } \\
\text { longa latência. }\end{array}$ & $\begin{array}{l}\text { Foi encontrado } \\
\text { aumento da } \\
\text { latência P300 } \\
\text { nos indivíduos } \\
\text { intoxicados por } \\
\text { organofosforado } \\
\text { em relação ao } \\
\text { grupo controle, } \\
\text { este aumento de } \\
\text { latência pode su- } \\
\text { gerir alteração do } \\
\text { sistema auditivo } \\
\text { central. }\end{array}$ & $\begin{array}{c}\text { Neste estudo, } \\
\text { comparando } \\
\text { as latências do } \\
\text { potencial auditivo } \\
\text { de longa latência } \\
\text { (P300) nos } \\
\text { grupos controle } \\
\text { e indivíduos } \\
\text { intoxicados com } \\
\text { organofosforado, } \\
\text { o valor de p foi } \\
\text { de 0,003 com } \\
\text { diferença média } \\
\text { de 39,9 (IC95\%: } \\
\text { 13,7-66,0), foi } \\
\text { realizado ajuste } \\
\text { para a variável } \\
\text { socioeconômica. }\end{array}$ \\
\hline
\end{tabular}

(continua) 
Tabela 1 (continuação)

\begin{tabular}{|c|c|c|c|c|c|c|c|c|c|}
\hline $\begin{array}{l}\text { Referência } \\
\text { (ano) }\end{array}$ & $\begin{array}{l}\text { População } \\
\text { exposta }\end{array}$ & $\begin{array}{l}\text { Substân- } \\
\text { cia quí- } \\
\text { mica }\end{array}$ & $\begin{array}{l}\text { Tipo de } \\
\text { estudo }\end{array}$ & $\begin{array}{l}\text { Tipo de } \\
\text { exposição }\end{array}$ & $n$ & $\begin{array}{c}\text { Forma de } \\
\text { mensuração da } \\
\text { exposição }\end{array}$ & $\begin{array}{c}\text { Instrumentos } \\
\text { de avaliação do } \\
\text { desfecho }\end{array}$ & Resultado & $\begin{array}{l}\text { Resultados } \\
\text { estatísticos }\end{array}$ \\
\hline $\begin{array}{l}\text { Dassa- } \\
\text { nayake et } \\
\text { al. } 40 \text { (2008) }\end{array}$ & $\begin{array}{c}\text { Fazendei- } \\
\text { ros }\end{array}$ & $\begin{array}{l}\text { Organo- } \\
\text { fosfora- } \\
\text { dos }\end{array}$ & $\begin{array}{l}\text { Estudo } \\
\text { de caso } \\
\text { controle }\end{array}$ & $\begin{array}{c}\text { Ocupacio- } \\
\text { nal }\end{array}$ & 73 & $\begin{array}{l}\text { Foram utilizados } \\
\text { dois grupos: } \\
\text { o primeiro de } \\
\text { aplicadores de } \\
\text { pesticidas, e } \\
\text { o segundo de } \\
\text { trabalhadores } \\
\text { do hospital e } \\
\text { pacientes onde } \\
\text { foi realizada a } \\
\text { pesquisa (grupo } \\
\text { controle). }\end{array}$ & $\begin{array}{c}\text { Pesquisa do } \\
\text { potencial } \\
\text { evocado auditivo } \\
\text { de média e longa } \\
\text { latências. }\end{array}$ & $\begin{array}{l}\text { Os fazendeiros } \\
\text { apresentaram } \\
\text { mais alterações } \\
\text { nos teste de } \\
\text { potencial } \\
\text { evocado de } \\
\text { longa latência, } \\
\text { apresentando } \\
\text { erros na } \\
\text { contagem de } \\
\text { oddball. A } \\
\text { latência dos } \\
\text { potenciais de } \\
\text { média e longa } \\
\text { latências (P300 } \\
\text { e N2) apresentou } \\
\text { diferença } \\
\text { estatística } \\
\text { significativa entre } \\
\text { os dois grupos, } \\
\text { sugerindo } \\
\text { alteração das vias } \\
\text { auditivas centrais. }\end{array}$ & $\begin{array}{c}\text { Neste estudo } \\
\text { foi observada } \\
\text { diferença } \\
\text { significativa } \\
\text { entre os grupos } \\
\text { controle e } \\
\text { agricultores } \\
\text { nos seguintes } \\
\text { resultados: } \\
\text { N200 (média } \\
\text { latência): } p= \\
\text { 0,019, diferença } \\
\text { de 14,2 (IC95\%: } \\
2,4-25,9) \text {, } \\
\text { P300 (longa } \\
\text { latência): } p= \\
0,0006, \text { diferença } \\
\text { de 32,1 (IC95\%: } \\
\text { 14,1-50,0). } \\
\text { Erros de } \\
\text { contagem (longa } \\
\text { latência): } p= \\
0,044, \text { diferença } \\
\text { de 1,5 (IC95\%: } \\
0,4-3,0 \text { ). }\end{array}$ \\
\hline $\begin{array}{l}\text { Foltz et al. } 33 \\
\text { (2010) }\end{array}$ & $\begin{array}{ll}3 & \text { Pilotos } \\
& \text { agrícolas }\end{array}$ & $\begin{array}{l}\text { Agrotóxi- } \\
\text { cos }\end{array}$ & $\begin{array}{l}\text { Estudo } \\
\text { de coorte } \\
\text { retrospec- } \\
\text { tiva }\end{array}$ & $\begin{array}{c}\text { Ocupacio- } \\
\text { nal }\end{array}$ & 41 & $\begin{array}{c}\text { Foi realizado } \\
\text { questionário para } \\
\text { avaliar o grau } \\
\text { de exposição } \\
\text { (mais expostos e } \\
\text { menos expostos), } \\
\text { os grupos foram } \\
\text { comparados en- } \\
\text { tre si. }\end{array}$ & $\begin{array}{l}\text { Questionário } \\
\text { sobre rotina } \\
\text { de trabalho } \\
\text { e audição e } \\
\text { audiometria } \\
\text { tonal. }\end{array}$ & $\begin{array}{c}\text { O estudo } \\
\text { concluiu que } \\
\text { pilotos agrícolas } \\
\text { apresentaram } \\
\text { um alto índice de } \\
\text { perda auditiva, } \\
\text { que pode trazer } \\
\text { prejuízo para } \\
\text { comunicação. } \\
\text { Tal atividade } \\
\text { ocupacional } \\
\text { envolve contato } \\
\text { com agrotóxicos } \\
\text { e nível alto de } \\
\text { ruído. }\end{array}$ & $\begin{array}{c}\text { Neste estudo } \\
\text { foi observada a } \\
\text { ocorrência de } \\
\text { perda auditiva } \\
\text { sugestiva } \\
\text { de PAIR em } \\
\text { 29,3\%. Quando } \\
\text { realizada a } \\
\text { análise estatística } \\
\text { multivariada } \\
\text { para o fator de } \\
\text { confundimento } \\
\text { de ruído e idade, } \\
\text { foi observada } \\
\text { tendência } \\
\text { estatística na } \\
\text { associação entre } \\
\text { configuração } \\
\text { audiométrica } \\
\text { e contato com } \\
\text { agrotóxico } \\
\text { (p = 0,088). }\end{array}$ \\
\hline
\end{tabular}

(continua) 


\begin{tabular}{|c|c|c|c|c|c|c|c|c|c|}
\hline $\begin{array}{l}\text { Referência } \\
\text { (ano) }\end{array}$ & $\begin{array}{l}\text { População } \\
\text { exposta }\end{array}$ & $\begin{array}{l}\text { Substân- } \\
\text { cia quí- } \\
\text { mica }\end{array}$ & $\begin{array}{l}\text { Tipo de } \\
\text { estudo }\end{array}$ & $\begin{array}{c}\text { Tipo de } \\
\text { exposição }\end{array}$ & $n$ & $\begin{array}{c}\text { Forma de } \\
\text { mensuração da } \\
\text { exposição }\end{array}$ & $\begin{array}{c}\text { Instrumentos } \\
\text { de avaliação do } \\
\text { desfecho }\end{array}$ & Resultado & $\begin{array}{l}\text { Resultados } \\
\text { estatísticos }\end{array}$ \\
\hline $\begin{array}{l}\text { Guida et } \\
\text { al. } 34 \text { (2010) }\end{array}$ & $\begin{array}{l}\text { Traba- } \\
\text { Ihadores } \\
\text { expostos } \\
\text { a ruído e } \\
\text { expostos } \\
\text { a ruído e } \\
\text { praguici- } \\
\text { das }\end{array}$ & $\begin{array}{l}\text { Pragui- } \\
\text { cidade } \\
\text { (produto } \\
\text { químico } \\
\text { Malathion) }\end{array}$ & $\begin{array}{l}\text { Estudo } \\
\text { de coorte } \\
\text { retrospec- } \\
\text { tiva }\end{array}$ & $\begin{array}{l}\text { Ocupacio- } \\
\text { nal }\end{array}$ & 80 & $\begin{array}{l}\text { Foram avaliados } \\
\text { dois grupos, o } \\
\text { primeiro com } \\
\text { exposição } \\
\text { somente a ruído, } \\
\text { e o segundo com } \\
\text { exposição a ruído } \\
\text { e praguicida. }\end{array}$ & $\begin{array}{l}\text { Análise de } \\
\text { prontuário } \\
\text { hospitalar e } \\
\text { audiometria } \\
\text { tonal. }\end{array}$ & $\begin{array}{l}\text { Os trabalhadores } \\
\text { expostos ao } \\
\text { ruído ocupacional } \\
\text { e aos praguicidas } \\
\text { possuem maior } \\
\text { risco de perda } \\
\text { auditiva do que } \\
\text { os expostos } \\
\text { somente ao } \\
\text { ruído. }\end{array}$ & $\begin{array}{c}\text { Neste estudo } \\
\text { foi observada } \\
\text { diferença } \\
\text { significativa entre } \\
\text { os grupos na } \\
\text { orelha esquerda } \\
\text { em } 3.000 \mathrm{~Hz} \\
\text { com valor de } \\
\text { p = 0,008 e na } \\
\text { frequência de } \\
4.000 \mathrm{~Hz} \text {, na } \\
\text { orelha direita } \\
\text { com valor de } \\
\text { p = 0,007 e na } \\
\text { orelha esquerda } \\
\text { com valor de } \\
\text { p = 0,023 para } \\
\text { os indivíduos } \\
\text { expostos ao ruído } \\
\text { e praguicidas. }\end{array}$ \\
\hline
\end{tabular}

IC95\%: intervalo de 95\% de confiança; OR: odds ratio; PA: perda auditiva; PAIR: perda auditiva induzida pelo ruído; RR: risco relativo; RT: razão de taxa.

Consensualmente, todos os estudos, considerando suas medidas de ocorrência/associação, encontraram correlação entre a exposição avaliada e alteração nas vias auditivas (periférica e/ ou central).

Todos os artigos analisados evidenciaram que a exposição ao agrotóxico induz ao dano periférico e/ou central e/ou à alteração cognitiva; nos artigos que avaliaram também o ruído, foi observado que este é um fator que potencializa os efeitos tóxicos.

Com relação à avaliação da qualidade metodológica (Tabela 2) dos artigos, as especificações de inclusão da população em todos os estudos foram feitas de maneira criteriosa. Sete trabalhos usaram um tamanho de amostra reduzido, sem justificá-lo; somente nove tiveram a presença de grupo controle. Com relação à qualidade da avaliação realizada para pesquisar as vias auditivas, quatro estudos utilizaram somente questionários, diminuindo a acurácia da avaliação, e um estudo usou audiometria tonal em apenas um quarto da população inicial de 1.727 indivíduos. Somente um dos estudos realizou a pesquisa de biomarcador, que foi feita por meio do estudo dos metabólitos. Todos os estudos obtiveram conclusões compatíveis com os resultados encontrados. Para avaliar o grau dos artigos foi dada uma pontuação variando de 0 a 8 a cada um deles, em que cada requisito valia um ponto. Foi considerado artigo de alta qualidade os que obtiveram nota de 7 a 8 pontos, os de moderada qualidade tiveram nota de 4 a 6 , e de baixa qualidade os que apresentaram nota de 1 a 3 pontos. A maioria dos artigos teve avaliação moderada por parte dos revisores, principalmente pelos seguintes motivos: ausência de grupo controle, avaliação exclusivamente realizada usando questionários e ausência de biomarcador.

\section{Discussão}

Apesar da busca exaustiva em bases de dados e do período coberto pela revisão (21 anos), foram encontrados apenas 16 trabalhos sobre o tema, dos quais apenas seis foram realizados no Brasil $10,31,32,33,34,35$, evidenciando o incipiente desenvolvimento da audiologia relacionada às substâncias químicas. O uso de agrotóxicos, principalmente em países subdesenvolvidos, vem aumentando a cada dia, sendo importantíssima a realização de estudos sobre a exposição ocupacional e ambiental.

Uma vez reconhecido que os agrotóxicos são neurotóxicos e que sua atuação pode ser lenta 
Descrição qualitativa dos estudos selecionados para a revisão sistemática.

\begin{tabular}{|c|c|c|c|c|c|c|c|c|c|}
\hline Referência & $\begin{array}{l}\text { Critérios de } \\
\text { inclusão da } \\
\text { população } \\
\text { exposta }\end{array}$ & $\begin{array}{c}\text { Tamanho } \\
\text { da amostra } \\
\text { estudada }\end{array}$ & $\begin{array}{c}\text { Utilização } \\
\text { de grupo } \\
\text { controle }\end{array}$ & $\begin{array}{c}\text { Ausência } \\
\text { de viés de } \\
\text { seleção }\end{array}$ & $\begin{array}{l}\text { Pesquisa } \\
\text { realizada } \\
\text { para avaliar } \\
\text { a audição }\end{array}$ & $\begin{array}{l}\text { Exposição } \\
\text { somente a } \\
\text { agrotóxico }\end{array}$ & $\begin{array}{l}\text { Presença de } \\
\text { biomarcador }\end{array}$ & $\begin{array}{c}\text { Resultado } \\
\text { concreto }\end{array}$ & $\begin{array}{c}\text { Pontuação } \\
\text { obtida }\end{array}$ \\
\hline Beckett et al. 37 & Sim & Sim & Não & Não & Sim & Não & Não & Sim & 4 \\
\hline Bosma et al. 48 & Sim & Sim & Sim & Não & Não & Não & Não & Sim & 4 \\
\hline Hwang et al. 52 & Sim & Sim & Não & Não & Não & Não & Não & Sim & 3 \\
\hline Gomez et al. 17 & Sim & Sim & Não & Não & Sim & Não & Não & Sim & 4 \\
\hline Teixeira et al. 31 & Sim & Não & Sim & Sim & Sim & Sim & Não & Sim & 6 \\
\hline Teixeira et al. 10 & Sim & Sim & Não & Não & Sim & Sim & Não & Não & 4 \\
\hline Manjabosco et al. 32 & Sim & Não & Sim & Sim & Sim & Sim & Não & Não & 5 \\
\hline Choi et al. 46 & Sim & Sim & Não & Não & Não & Não & Não & Sim & 3 \\
\hline Lizardi et al. 38 & Sim & Não & Não & Não & Não & Não & Sim & Sim & 3 \\
\hline Dassanayake et al. 39 & Sim & Não & Sim & Sim & Sim & Sim & Não & Sim & 6 \\
\hline Crawford et al. 47 & Sim & Sim & Sim & Não & Não & Não & Não & Sim & 4 \\
\hline Renick et al. 49 & Sim & Sim & Não & Não & Sim & Não & Não & Sim & 4 \\
\hline Dassanayake et al. 40 & Sim & Não & Sim & Não & Sim & Sim & Não & Sim & 5 \\
\hline Foltz et al. 33 & $\operatorname{Sim}$ & Não & Não & Sim & Sim & Sim & Não & Sim & 5 \\
\hline Guida et al. 34 & Sim & Não & Sim & Não & Sim & Não & Não & Sim & 4 \\
\hline Oliveira et al. 35 & Sim & Sim & Sim & Sim & Sim & Sim & Não & Sim & 7 \\
\hline
\end{tabular}

Sim: baixo risco de viés; Não: alto risco de viés.

e insidiosa 36 , encontramos apenas cinco estudos $31,37,38,39,40$ que avaliaram o sistema auditivo central e a grande maioria foi de estudos seccionais e não de coorte. A exposição a longo prazo produz alterações clínicas que muitas vezes não são detectadas no exame neurológico nem pelos marcadores biológicos e que, silenciosamente, modificam a vida do indivíduo exposto. Os sintomas subclínicos, considerados como sinal precoce da intoxicação, 41,42 podem ser avaliados por meio de exames neurofisiológicos e neuropsicológicos 43 , apresentando alterações tanto do sistema nervoso periférico como do central 44,45 .

Os trabalhos sobre os danos auditivos relacionados à saúde de trabalhadores eram associados quase que exclusivamente aos riscos de exposição ao ruído 11 , muitos estudos 10,32,33,34,46,47 que avaliaram o ruído foram utilizados na analise como um efeito confundidor e, sempre que presente, foi um fator que piorou os resultados, principalmente nas perdas auditivas periféricas. Outro fator usado como viés de confundimento foi a idade 35,47 , pois a presbiacusia pode interferir nos resultados.

Os sujeitos que foram incluídos nas pesquisas eram, em sua grande maioria, trabalhadores expostos de formas variadas à substância química, assim, não conseguimos chegar a um consenso sobre quais são as ocupações mais insalubres ou quais são as atividades que mais expõem os trabalhadores, mas é possível afirmar que a exposição aos agrotóxicos pode afetar as vias auditivas, principalmente as vias periféricas $10,30,32,46,48,49$, causando perda auditiva que prejudicará a comunicação.

É importante ficar atento porque não são só os agricultores estão expostos aos agrotóxicos, alguns estudos mostraram que outros profissionais como pilotos agrícolas 33 e pulverizadores de veneno da dengue estão sujeitos à ação dos agrotóxicos 10,31 .

A falta de descrição exata dos tipos de agrotóxicos utilizados corrobora com a literatura no consenso de que os agricultores utilizam vários tipos de agrotóxicos ao mesmo tempo, de variados graus de periculosidade 50 . Essa dificuldade dos pesquisadores em delimitar a substância química é um fator que restringe a avaliação clínica, o diagnóstico e o tratamento, principalmente se os marcadores biológicos não são aferidos nas pesquisas. Apenas um artigo utilizou tal instrumento de avaliação.

Pela heterogeneidade dos trabalhos, que estudaram faixas etárias muito diferentes, realizaram avaliações diversas (questionários di- 
ferentes, audiometria tonal, potencial evocado de curta latência, potencial evocado de média latência, potencial evocado de longa latência e teste de processamento auditivo central) e fizeram análises variadas (risco relativo, odds ratio, prevalência de perda auditiva), não foi possível realizar uma metanálise.

É necessário que sejam feitos novos estudos para avaliar principalmente as alterações que os agrotóxicos podem causar no sistema auditivo central e tentar correlacionar com os diferentes tipos de substâncias químicas (herbicidas, fungicidas, inseticidas, praguicidas etc.).

\section{Conclusão}

A diversidade das pesquisas demonstra que o monitoramento e a avaliação dos riscos causados pela exposição são múltiplos, com uma heterogeneidade importante. A maior dificuldade da literatura se encontra exatamente neste ponto, pois se torna difícil a comparação. Os estudos demonstram que os agrotóxicos são ototóxicos, lesando diversas áreas do sistema auditivo periférico e central.

\section{Resumen}

El objetivo de este artículo es presentar un estudio sobre el uso de la historia oral de vida como estrategia de aproximación entre cuidador y anciano, con el fin de contribuir a la humanización en la relación entre el profesional de la salud y el paciente. Se trata de una investigación cualitativa y descriptiva. Hemos reunido a siete ancianos, varones y mujeres, con más de 65 años que, a partir de entrevistas abiertas y semi-estructuradas, hicieron posible la producción de relatos de vida que, una vez finalizados, fueron devueltos a los colaboradores en forma de cuadernos personalizados para que ellos dispusieran de ellos como quisieran. Como resultado ha sido posible percibir que tal metodología contribuye a la generación de un vínculo entre enfermero y anciano, presentándose no solamente como ele mento humanizador, sino también terapéutico.

Praguicidas; Pérdida Auditiva; Pérdida Auditiva Central; Salud Ambiental; Revisión
Na medida em que esta revisão mostra evidência de associação entre exposição a agrotóxicos e alteração auditiva periférica e central, agravada com a exposição ao ruído, é importante que se faça um bom diagnóstico audiológico para que sejam aplicadas medidas preventivas para minimizarem ou acabarem com as intoxicações agudas e crônicas. A avaliação audiológica deve fazer parte dos exames periódicos dos trabalhadores expostos aos agrotóxicos. É importante que novos estudos sejam realizados para conseguir compreender a ação desses produtos químicos nas vias auditivas.

\section{Colaboradores}

Todos os autores conceberam, estruturaram e revisaram o artigo.

\section{Agradecimentos}

Agradecemos ao Programa de Pós-graduação do Instituto de Estudos em Saúde Coletiva da Universidade Federal do Rio de Janeiro pelo suporte para a formulação deste artigo. 


\section{Referências}

1. Londres F. Agrotóxicos no Brasil: um guia para ação em defesa da vida. Rio de Janeiro: Articulação Nacional de Agroecologia/Rede Brasileira de Justiça Ambiental; 2011.

2. Carneiro F, Soares V. Brasil é o país que mais usa agrotóxicos no mundo. http://www.ihu.unisinos. br/noticias/noticias-arquivadas/34124-brasil-e-opais-que-mais-usa-agrotoxicos-no-mundo (acessado em 08/Nov/2012).

3. Organização Pan-Americana da Saúde. Manual de vigilância da saúde de populações expostas a agrotóxicos. Brasília: Secretaria de Vigilância Sanitária, Ministério da Saúde; 1996.

4. Ronda E, Regidor E, García AM, Domínguez V. Association between congenital anomalies and paternal exposure to agricultural pesticides depending on mother's employment status. J Occup Environ Med 2005; 47:826-8.

5. Koifman S, Hatagima A. Exposição aos agrotóxicos e câncer ambiental. In: Peres F, Moreira JC, organizadores. É veneno ou é remédio? Agrotóxicos, saúde e meio ambiente. Rio de Janeiro: Editora Fiocruz; 2003. p. 75-100.

6. Eddleston M, Phillips MR. Self poisoning with pesticides. BMJ 2004; 7430:42-4.

7. Rupa DS, Reddy PP, Reddi OS. Reproductive performance in population exposed to pesticides in cotton fields in India. Environ Res 1991; 55:123-8.

8. Siqueira SL, Kruse MHL. Agrotóxicos e saúde humana: contribuição dos profissionais do campo da saúde. Rev Esc Enferm USP 2008; 42:584-90.

9. Morata TC, Dunn DE, Kretschmer LW, Lemasters GK, Keith RW. Effects of occupational exposure to organic solvents and nise on hearing. Scand J Work Environ Health 1993; 19:245-54.

10. Teixeira CF, Augusto LGS, Morata TC. Saúde auditiva de trabalhadores expostos a ruído e inseticidas. Rev Saúde Pública 2003; 37:417-23.

11. Atherley GR, Martin AM. Equivalent continuos noise level as a measure of injury from impact noise. Ann Occup Hyg 1971; 14:11-28.

12. AgrawalY, Platz EA, Niparko JK. Prevalence of hearing loss and differences by demographic characteristics among US adults. Arch Intern Med 2008; 168:1522-30.

13. Higgins JPT, Green S, editors. Cochrane handbook for systematic reviews of interventions version 5.1.0. The Cochrane Collaboration; 2011. http:// www.cochrane-handbook.org.

14. Thelin JW, Joseph DJ, Davis WE, Baker DE, Hosokawa MC. High-frequency hearing loss in male farmers of Missouri. Public Health Rep 1983; 98:268-73.

15. Karlovich RS, Wiley TL, Tweed T, Jensen DV. Hearing sensitivity in farmers. Public Health Rep 1988; 103:61-71.

16. Plakke BL, Dare E. Occupational hearing loss in farmers. Public Health Rep 1992; 107:188-92.

17. Gomez MI, Hwang SA, Sobotova L, Stark AD, May JJ. A comparison of self-reported hearing loss and audiometry in a cohort of New York farmers. J Speech Lang Hear Res 2001; 44:1201-8.

18. Solecki L. Hearing loss among private farmers in the light of current criteria for diminished sense of hearing. Ann Agric Environ Med 2002; 9:157-62.
19. Stewart M, Scherer J, Lehman ME. Perceived effects of high frequency hearing loss in a farming population. J Am Acad Audiol 2003; 14:100-8.

20. Kerr MJ, McCullagh M, Savik K, Dvorak LA. Perceived and measured hearing ability in construction laborers and farmers. Am J Ind Med 2003; 44:431-7.

21. Solecki L. Preliminary evaluation of occupational hearing loss risk among private farmers. Ann Agric Environ Med 2003; 10:211-5.

22. Williams W, Purdy S, Murray N, LePage E, Challinor K. Hearing loss and perceptions of noise in the workplace among rural Australians. Aust J Rural Health 2004; 12:115-9.

23. Miyakita T, Ueda A, Futatsuka M, Inaoka T, Nagano M, Koyama W. Noise exposure and hearing conservation for farmers of rural japanese communities. J Sound Vib 2004; 277:633-41.

24. Hass-Slavin L, McColl MA, Pickett W. Challenges and strategies related to hearing loss among dairy farmers. J Rural Health 2005; 21:329-36.

25. Yokoyama K. Our recent experiences with sarin poisoning cases in Japan and pesticide users with references to some selected chemicals. Neurotoxicology 2007; 28:364-73.

26. Carruth A, Robert AE, Hurley A, Currie PS. The impact of hearing impairment,perceptions and attitudes about hearing loss, and noise exposure risk patterns on hearing handicap among farm family members. AAOHN J 2007; 55:227-34.

27. Gates DM, Jones MS. A pilot study to prevent hearing loss in farmers. Public Health Nurs 2007; 24:547-53.

28. Eskenazi B, Marks AR, Bradman A, Harley K, Barr DB, Johnson C, et al. Organophosphate pesticide exposure and neurodevelopment in young Mexican-american children. Environ Health Perspect 2007; 115:792-8

29. Aybek A, Kamer HA, Arslan S. Personal noise exposures of operators of agricultural tractors. Appl Ergon 2010; 41:274-81.

30. Lower T, Fragar L, Depcynzksi J, Challinor K, Mills J, Williams W. Improving hearing health for farming families. Rural Remote Health 2010; 10:1350.

31. Teixeira CF, Augusto LGS, Morata TC. Occupational exposure to insecticides and their effects on the auditory system. Noise Health 2002; 4:31-9.

32. Manjabosco CW, Morata TC, Marques JM. Perfil audiométrico de trabalhadores agrícolas. Arq Int Otorrinolaringol 2004; 8:285-95.

33. Foltz L, Soares CD, Reichembac MAK. Perfil audiológico de pilotos agrícolas. Arq Int Otorrinolaringol 2010; 14:322-30.

34. Guida HL, Morini RG, Cardoso ACV. Avaliação audiológica em trabalhadores expostos a ruído e praguicidas. J Bras Otorrinol 2010; 76:423-7.

35. Oliveira CCC, Vargas MM, Sena TRR. Saúde auditiva e qualidade de vida em trabalhadores expostos a agrotóxicos. Ciênc Saúde Coletiva; no prelo.

36. Asmus CIRF, Ferreira HP. Epidemiologia e saúde do trabalhador. In: Medronho R, organizador. Epidemiologia. São Paulo: Editora Atheneu; 2002. p. 385-402. 
37. Beckett SS, Chamberlain D, Hallman E, May J Hwang SA, Gomez M, et al. Hearing conservation for farmers: source apportionment of occupational and environmental factors contributing. J Occup Environ Med 2000; 42:806-13.

38. Lizardi PS, O'Rourke MK, Morris RJ. The effects of organophosphate pesticide exposure on Hispanic children's cognitive and behavioral functioning. J Pediatr Psychol 2008; 33:1-11.

39. Dassanayake T, Gawarammana IB, Weerasinghe V, Dissanayake PS, Pragaash S, Dawson A, et al. Auditory event-related potential changes in chronic occupational exposure to organophosphate pesticides. Clin Neurophysiol 2009; 120:1693-8.

40. Dassanayake T, Weerasinghe V, Dangahadeniya U, Kularatne K, Dawson A, Karalliedde L, et al. Longterm event-related potential changes following organophosphurus insecticide poisoning. Clin Neurophysiol 2008; 119:144-50.

41. Leveridge YR. Pesticide poisoning in Costa Rica during 1996. Vet Hum Toxicol 2008; 40:42-4.

42. Gomes J, Lloyd O, Revitt MD, Basha M. Morbidity among farm workers in a desert country in relation to long-term exposure to pesticides. Scand J Work Environ Health 2008; 24:213-9.

43. Ellenhorn MJ. Ellenhorn's medical toxicology: diagnostic and treatment of human poisoning. 2nd Ed. Baltimore: William \& Wilkins; 1997.

44. Lal CS, Kumar V, Ranjan A, Das VN, Kumar N, Kishore K, et al. Evaluation of cholinesterase level in an endemic population exposed to malathion suspension formulation as a vector control measure. Mem Inst Oswaldo Cruz 2004; 99:219-21.

45. Araújo AJ, Lima JS, Moreira JC, Jacob SC, Soares MO, Monteiro MCM, et al. Exposição múltipla a agrotóxicos e efeitos à saúde: estudo transversa em amostra de 102 trabalhadores rurais. Ciênc Saúde Coletiva 2007; 12:115-30.
46. Choi SW, Peek-Asa C, Sprince NL, Rautiainen RH, Donham KJ, Flamme GA, et al. Hearing loss as a risk factor for agricultural injuries. Am J Ind Med 2005; 48:293-301.

47. Crawford JM, Hoppin JA, Michael SD, Alavanja CR, Blair A, Sandler DP, et al. Hearing loss among licensed pesticide applicators in the agricultural health study running title: hearing loss among licensed pesticide applicators. J Occup Environ Med 2008; 50:817-26.

48. Bosna H, van Boxtel MP, Ponds RW, Houx PJ, Jolles J. Pesticide exposure and risk of mild cognitive dysfunction. Lancet 2000; 356:912-3.

49. Renick KM, Crawford JM, Wilkins III JR. Hearing loss among Ohio farm youth: a comparison to a national sample. Am J Ind Med 2009; 52:233-9.

50. Hoshino ACH, Pacheco-Ferreira H, Taguchi CK, Tomita S, Miranda MF. A auto-percepção da saúde auditiva e vestibular de trabalhadores expostos a organofosforados. Rev CEFAC 2009; 11:681-7.

51. Jayasinghe SS, Pathirana KD. Effects of deliberate ingestion of organophosphate or paraquat on brain stem auditory-evoked potentials. J Med Toxicol 2011; 5:277-80

52. Hwang SA, Gomez MI, Sobotova L, Stark AD, May JJ, Hallman EM. Predictors of hearing loss in New York farmers. Am J Ind Med 2001; 40:23-31.

Recebido em 18/Jan/2013

Versão final reapresentada em 31/Mar/2013

Aprovado em 16/Abr/2013 